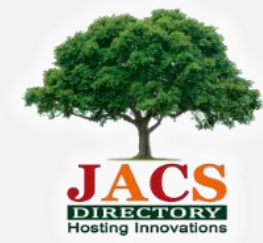

Journal of Nanoscience and Technology

Visit Journal at http://www.jacsdirectory.com/jnst

\title{
Study of Physical Properties of Nanocrystalline NiO Thin Films Prepared by Spray Pyrolysis Technique
}

\author{
H.S. Gavale1, M.S. Wagh¹, R.B. Ahirrao², S.R. Gosavi3,* \\ ${ }^{1}$ P.G. Department of Physics, Pratap College, Amalner - 425 401, Maharashtra, India. \\ ${ }^{2}$ Department of Physics, Arts and Science College Dahiwel - 424 304, Maharashtra, India. \\ ${ }^{3}$ Material Research Laboratory, C. H. C. Arts, S. G. P. Commerce, and B.B.J.P. Science College, Taloda - 425 413, Maharashtra, India.
}

\section{ART ICLE DETAILS}

\section{Article history:}

Received 12 January 2019

Accepted 27 January 2019

Available online 07 February 2019

\section{Keywords:}

Nickel Oxide

Spray Pyrolysis Technique

Optical Properties

\section{A B S T R A C T}

In this paper a systematic study has been carried out on the influence of thickness on the physical properties of nanocrystalline nickel oxide $(\mathrm{NiO})$ thin films prepared on glass substrate by spray pyrolysis method. The prepared nanocrystalline NiO films were characterized using X-ray diffraction technique (XRD), field emission scanning electron microscopy (FESEM) and optical measurement techniques. XRD patterns reveal the cubic structure for all the samples and the crystallite size varies with the thickness. FESEM images confirmed that all the films are homogeneous, without any crack, dense and exhibit almost complete coverage of the substrate. The optical parameters such as transmittance, absorption coefficient and energy band gap of the films as a function of film thickness was investigated by UV-Vis spectrophotometer. The band gap of the films is found to be direct allowed transition and the variation of band gap values of nanocrystalline $\mathrm{NiO}$ thin films were found to be in the range of $3.48 \mathrm{eV}$ to $3.53 \mathrm{eV}$.

\section{Introduction}

Metal oxides have been studied extensively over the last few decades due to their actual and potential applications in the science and technology. Due to their interesting optical and electrical properties, nickel oxide $(\mathrm{NiO})$ is one of the metal oxides which has been investigated for applications in sensors [1], UV photo-detector [2], in polymer bulkheterojunction solar cells [3], organic light emitting diodes [4], photo anode for $\mathrm{O}_{2}$ evolution [5], perovskite heterojunction solar cells [6] etc. $\mathrm{NiO}$ is a p-type, semitransparent and wide band gap transition metal oxide material widely used as a nontoxic material showing antiferromagnetic behavior [1,7].

Numerous techniques have been employed for the preparation of good quality $\mathrm{NiO}$ thin films. These include chemical bath deposition [8, 9], SILAR [10], sol-gel dip coating [11], potentiostatic electrodeposition [12], spin coating [13], electro-hydrodynamic atomization (EHDA) [14], spray pyrolysis [7, 15-17], e-beam evaporation [18], radio frequency magnetron sputtering [19], metal organic chemical vapor deposition (MOCVD) [20].

Depending on the application of interest, many efforts have been conducted to obtain the thin films with desirable physical properties with the above-mentioned thin film deposition techniques. The low-cost spray pyrolysis technique is a simple and versatile method for the preparation of $\mathrm{NiO}$ thin films with good optical and electronic properties [17]. Large area coating, by spraying the precursor solutions along with the carrier gas or by spraying the mixture directly on the heated surface of the substrate, becomes possible by using the spray pyrolysis technique [16]. The present work is focused on the preparation of good quality nanocrystalline $\mathrm{NiO}$ thin films using simple and economical spray pyrolysis technique. The effect of thickness on the structural, morphological and optical properties of nanocrystalline $\mathrm{NiO}$ films have been investigated and presented systematically in this paper.

\section{Experimental Methods}

Nanocrystalline NiO thin films were prepared on commercially available microscopic glass substrates $(25 \mathrm{~mm} \times 75 \mathrm{~mm} \times 1.35 \mathrm{~mm})$ using simple spray pyrolysis technique. Prior to deposition, the glass substrates were cleaned by using soap solution followed by chromic acid, acetone and deionized water as per the standard procedure. Finally, cleaned glass substrates were dried in oven.

An appropriate quantity of nickel chloride hexahydrate $\left(\mathrm{NiCl}_{2} \cdot 6 \mathrm{H}_{2} \mathrm{O}\right)$ (Loba Chemie, $99 \%$ purity) as a precursor of $\mathrm{Ni}$ and deionized water as a solvent were used as a source material for preparation of nanocrystalline $\mathrm{NiO}$ films using spray pyrolysis technique. $\mathrm{NiO}$ films were prepared by spraying a homogeneous mixture of aqueous solution with $0.01,0.05,0.10$ and $0.15 \mathrm{M} \mathrm{NiCl}_{2} .6 \mathrm{H}_{2} \mathrm{O}$ using compressed air as a carrier gas through a glass nozzle of $0.1 \mathrm{~mm}$ bore diameter on the pre-cleaned and pre-heated amorphous glass substrates kept at $350^{\circ} \mathrm{C} \pm 5{ }^{\circ} \mathrm{C}$. The distance between the nozzle and the substrate was $28 \mathrm{~cm}$. Film thickness was measured by using the weight difference method considering the density of the bulk nickel oxide. The structural, morphological and optical properties of the prepared nanocrystalline $\mathrm{NiO}$ films were carried out using X-ray diffraction (XRD) method in the $2 \theta$ ranging between $20^{\circ}$ to $80^{\circ}$ using Bruker AXS, Germany (D8 Advanced) X-ray diffractometer, field emission scanning electron microscope (FESEM, S-4800 Type-II, Hitachi High Technology Corporation Tokyo, Japan) and JASCO UV-VIS spectrophotometer (V-630) respectively.

\section{Results and Discussion}

The variation of nanocrystalline $\mathrm{NiO}$ film thickness studied as a function of $\mathrm{Ni}$ concentration in order to study the growth kinetics of the prepared films. Fig. 1 shows the variation of $\mathrm{NiO}$ film thickness versus $\mathrm{Ni}$ concentration.

It has been found that thickness of the films increases as the $\mathrm{Ni}$ concentration is increased to $0.1 \mathrm{M}$ and then it is decreased when $\mathrm{Ni}$ concentration is $0.15 \mathrm{M}$. This shows that the maximum thickness exhibited by nanocrystalline $\mathrm{NiO}$ films prepared with $0.1 \mathrm{M}$ concentration of precursor solution.

The XRD spectra of nanocrystalline $\mathrm{NiO}$ thin films of different thickness prepared by using spray pyrolysis technique are shown in Fig. 2(a-d). The XRD patterns clearly showed the influence of the film thickness on the crystallinity of the nanocrystalline $\mathrm{NiO}$ films. For all NiO films, the cubic structure characterized with $\left(\begin{array}{lll}1 & 1 & 1\end{array}\right)$ plane as preferred orientation, are identified with the standard JCPDS data [JCPDS card No. 73-1519]. Similar type of XRD pattern were found by Belahssen et. al. [21] for undoped NiO 
films prepared by using nickel nitrate as a Ni precursor. As a result of increase in film thickness, there is change in the intensity of the peak corresponding to the $2 \theta \approx 37.26^{\circ}$ were observed. It is observed that the crystallite size increases from $16.31 \mathrm{~nm}$ to $18.48 \mathrm{~nm}$ as film thickness increases from $120 \mathrm{~nm}$ to $210 \mathrm{~nm}$ and again it decreases to $16.44 \mathrm{~nm}$ for film thickness of $205 \mathrm{~nm}$.

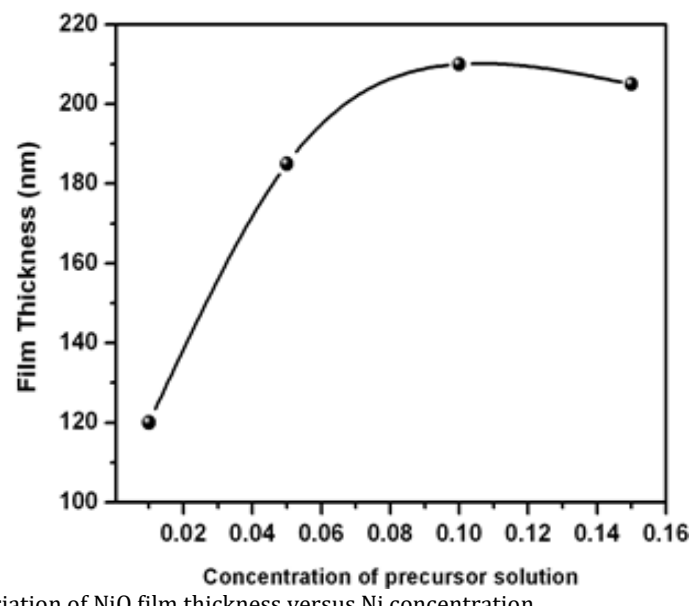

Fig. 1 Variation of NiO film thickness versus Ni concentration
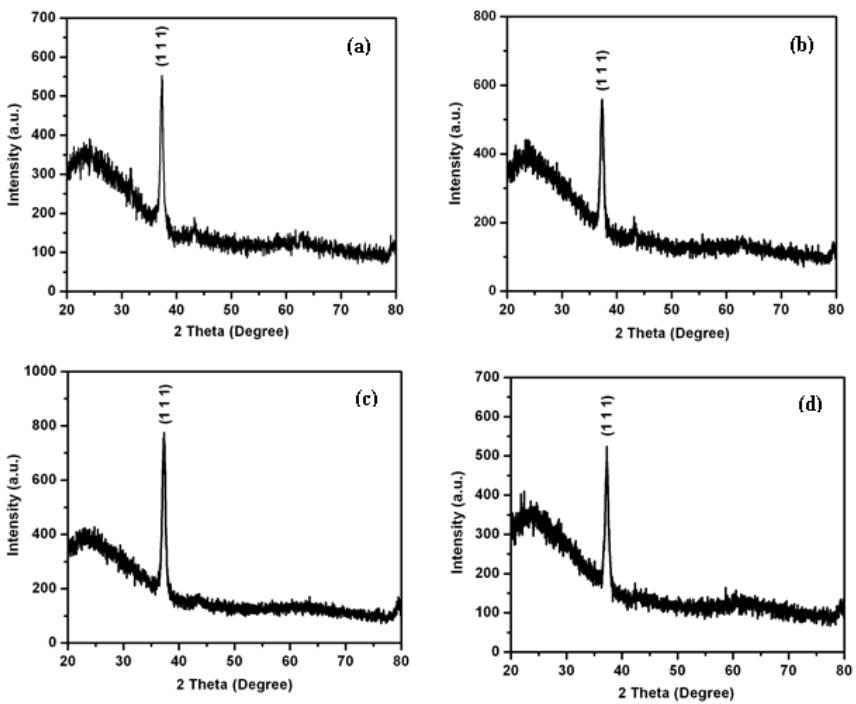

Fig. 2 XRD patterns of nanocrystalline $\mathrm{NiO}$ thin films deposited with different thickness (a) $120 \mathrm{~nm}$, (b) $185 \mathrm{~nm}$, (c) $210 \mathrm{~nm}$, (d) $205 \mathrm{~nm}$
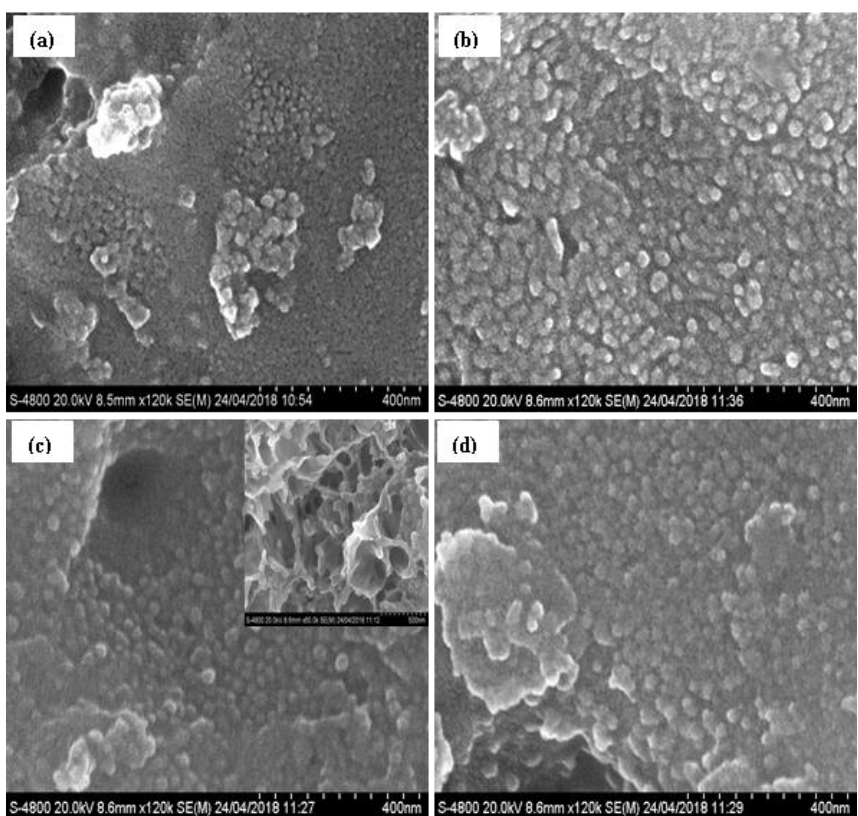

Fig. 3 FESEM images of nanocrystalline NiO thin films of different thickness (a)120 $\mathrm{nm}$, (b) $185 \mathrm{~nm}$, (c) $210 \mathrm{~nm}$, (d) $205 \mathrm{~nm}$
The topographical and elemental information of sprayed nanocrystalline NiO films was done by FESEM analysis. FESEM images of $\mathrm{NiO}$ films of different thickness are shown in Fig. 3(a-d). It can been seen that all the films are homogeneous and crack free. Also prepared material covering entire substrate surface area and microstructure consists of many round shaped grains, however there is a agllomeration in certain regions of the film which is clearly seen in the FESEM images. However porous surface morphology was observed in FESEM image of nanocrystalline $\mathrm{NiO}$ films with higher thickness as shown in inset of Fig. $3 c$. Such kind of morphology is very useful for gas sensing. The EDS spectra of nanocrystalline $\mathrm{NiO}$ thin films with higher thickness is as shown in Fig. 4. The analysis confirms the prsence of $\mathrm{Ni}$ and $\mathrm{O}$ elements with the ratio of 40:60. This confirms that the prepared $\mathrm{NiO}$ films is oxygen rich. It is very important to note that additional peaks attributed to Si are observed in EDS spectra which might be due to the glass substrate.

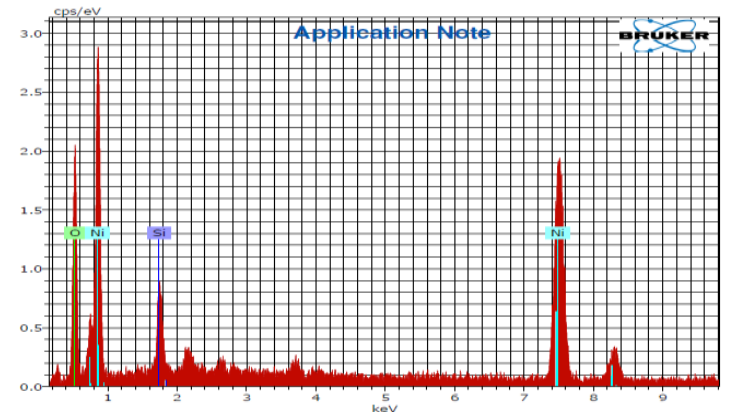

Fig. 4 EDS spectra of nanocrystalline nickel oxide thin films of thickness $210 \mathrm{~nm}$

The optical transmittance and absorption spectra of the sprayed nanocrystalline $\mathrm{NiO}$ films was determined by UV-Vis spectrophotometer. The optical transmittance and absorption of the all samples are shown in Figs. 5 and 6 respectiely. From transmittance spectra it is observed that the prepared $\mathrm{NiO}$ thin films exhibit high trnasmittance, ranging between $65-80 \%$ in the near infrared wavelength region. Further, we found that the transmittance of $\mathrm{NiO}$ thin films is decreased with the increase of thickness upto $210 \mathrm{~nm}$ and for higher film thickness it is again increased. This is in good agreement with the XRD results where we have observed the change in crystallite size with the thickness. The absorption spectra were used to determine the band gap values of the nanocrystalline $\mathrm{NiO}$ thin films using the Tauc relationship $[7,22]$.

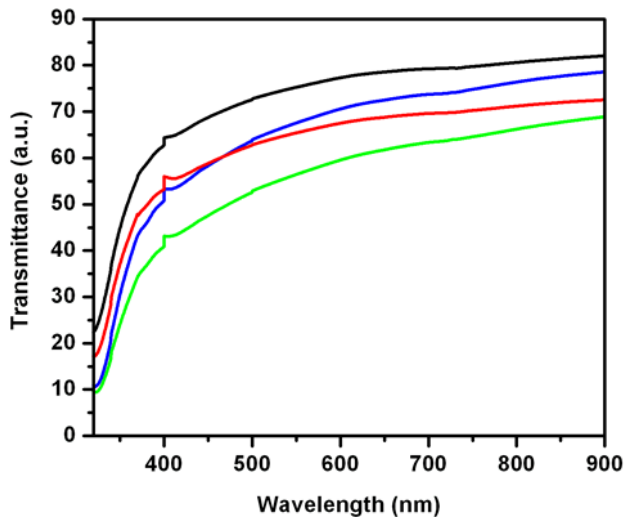

Fig. 5 Transmittance spectra for nanocrystalline NiO thin films of different thicknesses

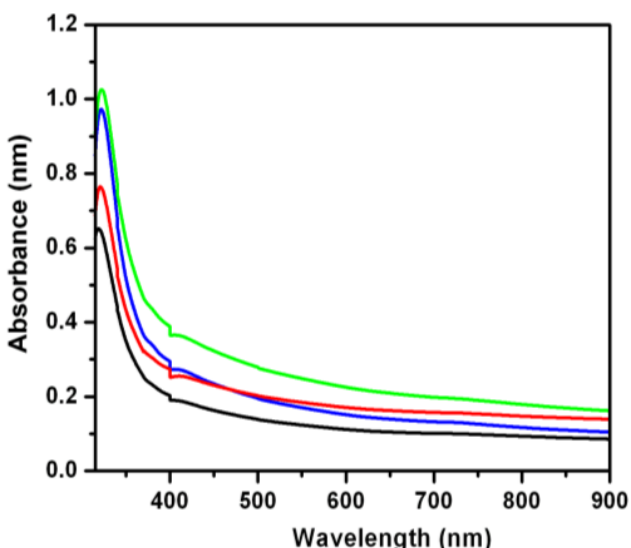

Fig. 6 Absorbance spectra for nanocrystalline NiO thin films of different thicknesses 
The band gap has been calculated by extrapolating the linear region of the plot of $(\alpha h v)^{2}$ versus $h v$ on the energy axis. Fig. 7 shows typical plot of $(\alpha h v)^{2}$ versus $h v$ for nanocrystalline NiO thin films with film thickness of $210 \mathrm{~nm}$ deposited using simple spray pyrolysis technique. The linear fit of the plot indicates the existence of the allowed direct band-gap transition. The band gap value of the $\mathrm{NiO}$ films is found to be $3.48 \mathrm{eV}$. The reported value of the band gap is in good agreement with the value reported previously [7]. Initially the band gap value is decreased with increase of thickness up to $210 \mathrm{~nm}$ and again increased for NiO film of $205 \mathrm{~nm}$ thickness.

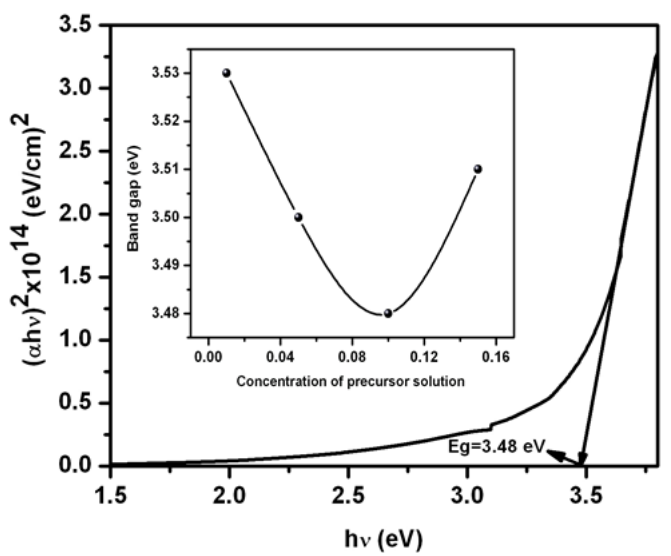

Fig. 7 Plot of $(\alpha h v)^{2}$ versus hu for nanocrystalline NiO thin films with $210 \mathrm{~nm}$ thickness

\section{Conclusion}

$\mathrm{NiO}$ thin films with different thickness have been successfully deposited by the simple and cost-effective spray pyrolysis technique. Increase in the thickness of the $\mathrm{NiO}$ films increased the crystallinity as well as morphological properties. It is also observed from the transmittance spectra that for lesser thickness, the average transmittance in the visible region is found to be $80 \%$ and it varies with the film thickness. Direct band gap values of $\mathrm{NiO}$ thin films were found to in the range of $3.48 \mathrm{eV}$ to 3.53 $\mathrm{eV}$ indicating that the properties of $\mathrm{NiO}$ films can be easily tailored by simply varying the film thickness.

\section{Acknowledgements}

The author sincerely acknowledges University Department of Chemical Technology (UDCT), North Maharashtra University Jalgaon for providing the characterization facilities. The author also gratefully acknowledges Principal, Pratap College Amalner and Principal Dr. P. V. Ramaiah, Secretary of Arts and Commerce College Trust, Taloda for his constant encouragement and kind support in the research activity.

\section{References}

[1] I. Hotovy, L. Spiess, M. Predanocy, V. Rehacek, J. Racko, Sputtered nanocrystalline NiO thin films for very low ethanol detection, Vacuum 107 (2014) 129-131.
[2] M.A. Abbasi, Z.H. Ibupoto, A. Khan, O. Nur, M. Willander, Fabrication of UV photo-detector based on coral reef like p-NiO/n-ZnO nanocomposite structures, Mater. Lett. 108 (2013) 149-152.

[3] M.D. Irwin, D.B. Buchholz, A.W. Hains, R.P.H. Chang, T.J. Marks, p-Type semiconducting nickel oxide as an efficiency-enhancing anode interfacial layer in polymer bulk-heterojunction solar cells, Proc. Nat. Acad. Sci. 105(8) (2008) 2783-2787.

[4] I.M. Chan, F.C. Hong, Improved performance of the single-layer and doublelayer organic light emitting diodes by nickel oxide coated indium tin oxide anode, Thin Solid Films 450 (2004) 304-311.

[5] Min-Joon Park, Jin-Young Jung, Sun-Mi Shin, Jae-Won Song, Yoon-Ho Nam, et al., Photoelectrochemical oxygen evolution improved by a thin $\mathrm{Al}_{2} \mathrm{O}_{3}$ interlayer in a $\mathrm{NiO}_{\mathrm{x}} / \mathrm{n}$-Si photoanode, Thin Solid Films 599 (2016) 54-58.

[6] K.C. Wang, P.S. Shen, M.H. Li, S. Chen, M.W. Lin, et al., Low-temperature sputtered nickel oxide compact thin film as effective electron blocking layer for mesoscopic $\mathrm{NiO} / \mathrm{CH}_{3} \mathrm{NH}_{3} \mathrm{PbI}_{3}$ perovskite heterojunction solar cells, ACS Appl. Mater. Interf. 6(15) (2014) 11851-11858.

[7] R. Sharma, A.D. Acharya, S.B. Shrivastava, T. Shripathi, V. Ganesan, Preparation and characterization of transparent $\mathrm{NiO}$ thin films deposited by spray pyrolysis technique, Optik 125 (2014) 6751-6756.

[8] U.M. Patil, R.R. Salunkhe, K.V. Gurav, C.D. Lokhande, Chemically deposited nanocrystalline NiO thin films for supercapacitor application, Appl. Surf. Sci. 255 (2008) 2603-2607.

[9] S. Sagadevana, S. Rajesh, I. Das, Studies on nanocrystalline nickel oxide thin films for potential applications, Mater. Today Proc. 4 (2017) 4123-4129.

[10] G.S. Gund, C.D. Lokhande, Ho Seok Park, Controlled synthesis of hierarchical nanoflake structure of $\mathrm{NiO}$ thin film for supercapacitor application, Jour. Alloy. Comp. 741 (2018) 549-556.

[11] A. Sawaby, M.S. Selim, S.Y. Marzouk, M.A. Mostafa, A. Hosny, Structure, optical and electrochromic properties of NiO thin films, Physica B 405 (2010) 3412 3420 .

[12] B. Ortiz-Cruz, M.A. Garcia-Lobato, E.R. Larios-Dur'an, E.M. M'uzquiz-Ramos, J.C Ballesteros-Pacheco, Potentiostatic electrodeposition of nanostructured $\mathrm{NiO}$ thin films for their application as electrocatalyst, Jour. Electroanal. Chem. 772 (2016) 38-45.

[13] T. Chtouki, L. Soumahoro, B. Kulyk, H. Bougharraf, B. Kabouchi, et al., Comparison of structural, morphological, linear and nonlinear optical properties of $\mathrm{NiO}$ thin films elaborated by spin-coating and spray pyrolysis, Optik 128 (2017) 8-13.

[14] N. Duraisamy, A. Numan, K. Ramesh, K.H. Choi, S. Ramesh, S. Ramesh Investigation on structural and electrochemical properties of binder free nanostructured nickel oxide thin film, Mater. Lett. 161 (2015) 694-697.

[15] P. Nazari, S. Gharibzadeh, F. Ansari, B. Abdollahi Nejand, M. Eskandari, et al., Facile green deposition of nanostructured porous $\mathrm{NiO}$ thin film by spray coating, Mater. Lett. 190 (2017) 40-44.

[16] K. Sajilal, A. Moses Ezhil Raj, Effect of thickness on structural and magnetic properties of $\mathrm{NiO}$ thin films prepared by chemical spray pyrolysis (CSP)technique, Mater. Lett. 164 (2016) 547-550.

[17] B.A. Reguig, A. Khelil, L. Cattin, M. Morsli, J.C. Bernéde, Properties of NiO thin films deposited by intermittent spray pyrolysis process, Appl. Surf. Sci. 253 (2007) 4330-4334.

[18] D.R. Sahu, Tzu-Jung Wu, Sheng-Chang Wang, Jow-Lay Huang, Electrochromic behavior of $\mathrm{NiO}$ films prepared by e-beam evaporation, Jour. Sci. Adv. Mater. Device. 2(2) (2017) 225-232.

[19] R. Kumar, C. Baratto, G. Faglia, G. Sberveglieri, E. Bontempi, L. Borgese, Tailoring the textured surface of porous nanostructured $\mathrm{NiO}$ thin films for the detection of pollutant gases, Thin Solid Films 583 (2015) 233-238.

[20] T.M. Roffi, S. Nozaki, K. Uchida, Growth mechanism of single-crystalline NiO thin films grown by metal organic chemical vapor deposition, Jour. Cryst. Growth 451 (2016) 57-64.

[21] O. Belahssen, M. Ghougali, A. Chala, Effect of iron doping on physical properties of NiO thin films, Jour. Nano Electron. Phys. 10(2) (2018) 02039-1-4.

[22] J.I. Pankove, Optical processes in semiconductors, Dover Publications, New York, 1971. 